\title{
Genetic Variations within and between Blue Crab (Portunus trituberculatus) Groups
}

\author{
Young-Jae Song and ${ }^{\dagger}$ Jong-Man Yoon \\ Department of Aquatic Life Medicine, College of Ocean Science and Technology, Kunsan National University, Gunsan \\ 54150, Korea
}

Received: June 12, 2021

Revised: August 9, 2021

Accepted: September 3, 2021

${ }^{+}$Corresponding author Jong-Man Yoon

Department of Aquatic Life Medicine, College of Ocean Science and Technology, Kunsan National University, Gunsan 54150, Korea.

Tel: +82-63-469-1887

E-mail:jmyoon@kunsan.ac.kr

Copyright $\odot 2021$ The Korean Society of Developmental Biology.

This is an Open Access article distributed under the terms of the Creative Commons Attribution Non-Commercial License (http://creativecommons.org/licenses/ by-nc/4.0/) which permits unrestricted non-commercial use, distribution, and reproduction in any medium, provided the original work is properly cited.

ORCID

Young-Jae Song

https://orcid.org/0000-0003-4756-2521 Jong-Man Yoon

https://orcid.org/0000-0003-2825-681X

Conflict of interests

The author declares no potential conflict of interest.

Acknowledgements

Not applicable.

Authors' contributions Conceptualization: Song YJ, Yoon JM

Data curation: Song YJ, Yoon JM Formal analysis: Song YJ, Yoon JM

Methodology: Song YJ, Yoon JM

Software: Song YJ, Yoon JM

Validation: Song YJ, Yoon JM

Investigation: Song YJ, Yoon JM

Writing-original draft: Yoon JM

Writing-review \& editing: Yoon JM

Ethics approval

This article does not require IRB/IACUC

\section{Abstract}

The five oligonucleotide primers (oligo-primers) turned out a total of 335 fragments (FMs) $(52.9 \%)$ in the blue crab (Portunus trituberculatus) group alpha and $298 \mathrm{FMs}(47.1 \%)$ in the crab group beta, with the FM scales range varying from $100 \mathrm{bp}$ to $2,000 \mathrm{bp}$. The highest band-sharing (BS) value (0.907) was found between individual's no. 19 and no. 20 within the blue crab group beta. Parties in the blue crab group beta $(0.601 \pm 0.017)$ had higher BS rates than did parties from the crab group alpha $(0.563 \pm 0.017)(p<0.05)$. The polar dendrogram got by the five oligo-primers points out two genetic extents: bundle I (BLUECRAB 01, 03, 04, 05, 06, 08, and 10) and bundle II (BLUECRAB 02, 07, 09. 11, 12, 13, 14, 15, 16, 17, 18, 19, 20, 21 , and 22). The OPD-01 primer revealed 22 loci shared by all the examples of the as FMs of $1,000 \mathrm{bp}$. The oligo-primer OPA-05 made unique loci shared to each group (ULSEG), almost $400 \mathrm{bp}$ and $500 \mathrm{bp}$, individually, in blue crab group beta. The remaining oligo-primers did not reveal any loci shared by the two crab groups (LSTG). The average number of ULSEG was diverse and 1.6-fold higher in the crab group beta than in the crab group alpha.

Keywords: Blue crab, Genetic group, Polar dendrogram, Portunus trituberculatus, Similarity matrices

\section{INTRODUCTION}

The particular markers definite to breed, species, genus or geographical group have been engaged in the identification of parties, species and populations and genetic diagnostics (Archak et al., 2003; Nagarajan et al., 2006; Yoon et al., 2006; Kim \& Yoon, 2018; Yoon, 2019a). So far, specific fragments (FMs) created by PCR by means of primers were deliberated to be a trustworthy method for discovering DNA relationship between organisms (Eujayl et al., 1998; Almeida et al., 2003; Archak et al., 2003; Liu \& Cordes, 2004; Wang \& Li, 2004; Wasko et al., 2004; Bernardet et al., 2005; Yamazaki et al., 2005; Yue \& Orban, 2005; Nagarajan et al., 2006; Yoon et al., 2006).

Blue crab (Portunus trituberculatus) is the most commonly eaten portunid crab in Korea all the year round, owing to the sweet taste. The crab is one of economically important crab species, belonging to the family Portunidae, and the order Decapoda. In the natural ecosystem, blue crab is widely distributed in the seawater areas of the Korean peninsula, as well as in several areas in China, Japan, Taiwan and the Americas. Morphologically, the crab has very large and long both claws and the body color of this crab 
approval because there are no human and animal participants. is dark purple with blue patterns. An investigate has shown that water temperature, feed volume, water width and salinity factors are critical in the early larval development of this portunid crab (Pyen, 1970). Largely, the dimension, style and pigment of this crab species differs along with territory, such as marsh and seawater zone, the nourishment, water temperature, and other shared factors. The preservative desires and tolerances of the crab species from different geographic areas are currently unknown, as is crab species discernment. As the crab culture industry develops, the comprehension of the inheritances of this crab species becomes more necessary; to evaluate the veiled genetic properties induced by crab production tasks.

There have been few genetic and molecular-biological studies of this kind of invertebrates, which are acknowledged as significant alimentary (Cho, 2007; Kim \& Park, 2014), environmentally (Kang, 1997; Yeon et al., 2011), managementally (Lee \& Yang, 2005), phylogenetically (Cho et al., 2009), and reproductively (Seo et al., 2009; Jo et al., 2013) compared to other crustacean species. Nonetheless, notwithstanding their commercial and technical values, a little report data presently exist about the genetics and early development of this crab species in Korea. So, there is a necessity to comprehend the genetic traits and more information of this crab group so as to assess accurately the precisely inherited implication.

This study efforts to explicate the genetic distances (GD) and differences within and between blue crab groups. In order to accomplish this, this author performed clustering analyses of blue crab (P. trituberculatus) in the Yellow Sea of Korea.

\section{MATERIALS AND METHODS}

Two groups of blue crab (P. trituberculatus) were obtained from Taean of the Yellow Sea of Korea. Two groups of crab muscle was collected in sterile tubes, immediately placed on freezing materials, and deposited at $-79^{\circ} \mathrm{C}$ up to necessary. PCR study was executed the genomic DNAs from 22 parties, utilizing altered five primers. The extraction/purification of genomic DNA was performed under the conditions described previously (Yoon et al., 2012). Proteinase K solution was added to the tubes and gently pipetted for a few minutes.

The $\mathrm{G}+\mathrm{C}$ content of the oligonucleotides primers (Operon Technologies, Alameda, CA, USA) was between 60\%-70\%. OPA-05 (5'-AGGGGTCTTG-3'), OPB-06 (5'-GGTGACGCAG-3'), OPD-01 (5'-ACCGCGAAGG-3'), OPD-07 (5'-TTGGCACGGG-3'), and OPD-14 (5'-CTTCCCCAAG-3') were the primers used to identify the unique loci shared to each group (ULSEG) and the number of loci shared by the two crab groups (LSTG) was calculated. PCR analysis was performed on an input DNA thermal cycler (MJ Research, Waltham, MA, USA). DNA amplification was performed with $25 \mu \mathrm{L}$ sample tubes containing $10 \mathrm{ng}$ of template DNA, $22 \mu \mathrm{L}$ of premix (Bioneer, Daejeon, Korea), and 1 unit of primer. PCR products of the amplification reaction were separated by electrophoresis for $30 \mathrm{~min}$ at $100 \mathrm{~V}$ in a $1.4 \%$ agarose gel, stained with ethidium bromide and visualized under UV light, and photographed on a transilluminator using a gel documentation system (PECA Products, Beloit, WI, USA).

Similarity matrices were established based on the data of band-sharing (BS) rates constructed by molecular analysis. Comparing the two lanes, the BS rate was calculated as follows: $\mathrm{BS}=2$ (Nab) / $(\mathrm{Na}+\mathrm{Nb})$, where $\mathrm{Nab}$ designates the number of FMs shared by examples $\mathrm{b}$ and $a ; \mathrm{Na}$ indicates the total number of FMs in a; and $\mathrm{Nb}$ represents the total number of FMs in example b. The average within-group correspondence was measured via pairwise parallel analysis between the parties within a group. A hierarchical polar dendrogram was constructed based on similarity matrices to yield a cluster tree using Systat version 10 (SPSS, Chicago, IL, USA). 


\section{RESULTS AND DISCUSSION}

Genomic DNA isolated from two groups of blue crab (P. trituberculatus) was amplified several times by PCR reactions. The complexity of the banding profiles varied greatly between the primers derived from the two blue crab groups. Generally speaking, using a variety of primers, PCR has been applied to identify polymorphic/specific markers particular to breed, line, species and geographical group, for identification of inherited multiplicity in varied species of entities (Eujayl et al., 1998; Almeida et al., 2003; Araneda et al., 2005; Bernardet et al., 2005; Yamazaki et al., 2005; Yoon et al., 2006; Yoon, 2019a\&b).

The FM numbers in each scale range were based on the integrated FMs amplified by the five primers, as shown in Fig. 1. The scale of the DNAFRs also varied widely, from $100 \mathrm{bp}$ to 2,000 bp, as indicated in Fig. 1. Higher FM scales ( $>2,000$ bp) are not observed in the two blue crab groups. These results, in fact, indicate that the genome scales of blue crab are in line with to those of the blue catfish (Liu et al., 1998), yellowfin tuna (Diaz-Jaimes \& Uribe-Alcocer, 2003), long-fin carp (Wang \& Li, 2004), masu salmon (Yamazaki et al., 2005), crayfish (Yoon et al., 2006), cuttlefish (Yoon \& Kim, 2010), and white clam (Yoon et al., 2012), and masu salmon (Yoon, 2020). With respect to various fishes, it has been reported that the number of amplified bands varied from three to eight, with the scale range varying from 500 to $3,530 \mathrm{bp}$ in three Channa punctatus groups (Nagarajan et al., 2006). They stated that the total number of bands observed ranged from 34 in the Quilon group to 37 in the Thirunelveli group. Polymorphisms are determined by primers or/and by the banding patterns of amplified products at specific positions (Eujayl et al., 1998; Yoon \& Kim, 2001; Diaz-Jaimes \& Uribe-Alcocer, 2003; Wang \& Li, 2004; Wasko et al., 2004; Araneda et al., 2005; Yamazaki et al., 2005; Yoon et al., 2006; Yoon \& Kim, 2010; Yoon et al., 2012; Yoon, 2019a).

The five oligonucleotide primers yielded a total of $335 \mathrm{FMs}$ (52.9\%) in the blue crab group alpha and $298 \mathrm{FMs}$ (47.1\%) in the blue crab group beta, with DNA FM scales ranging from 100 bp to 2,000 bp. The total number of bands observed ranged from 34 in the Quilon group to 37 in

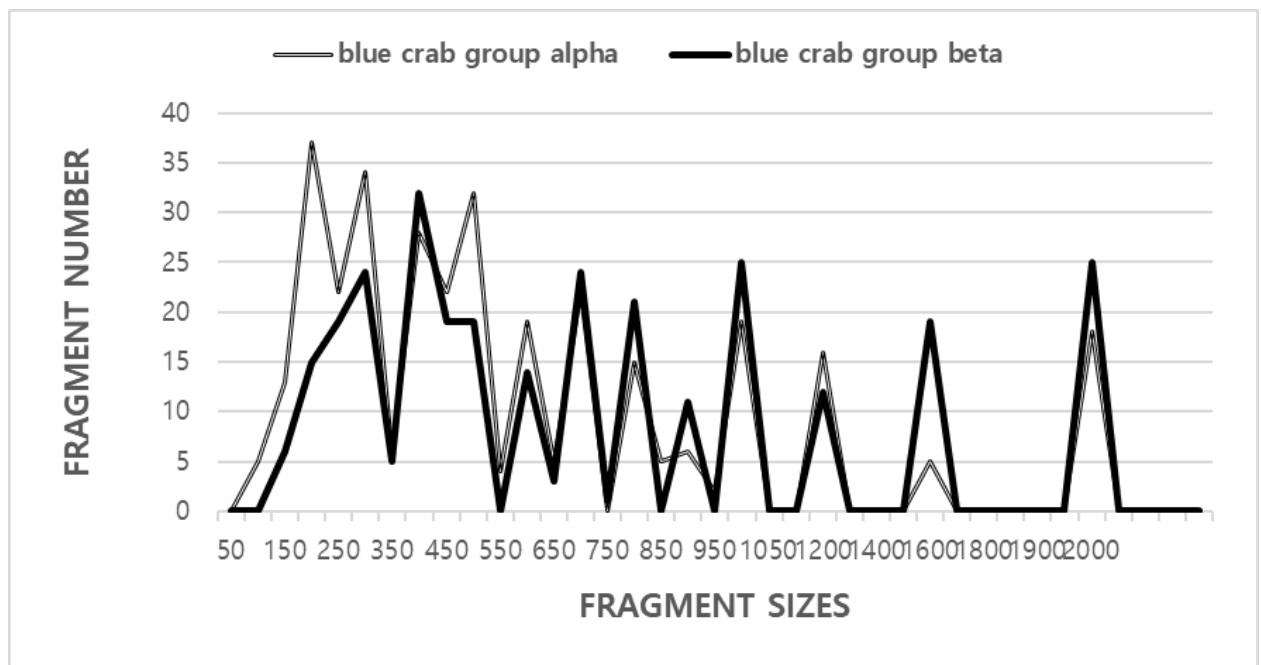

Fig. 1. The total number of FMs observed ranged from $335 \mathrm{FMs}$ in the blue crab group alpha to $298 \mathrm{FMs}$ in the blue crab group beta, separately. Solid grey lines: blue crab group alpha (SWIMCRAB01, 02, 03, 04, 05, 06, 07, 08, 09, 10, and 11). Solid black lines (SWIMCRAB12, 13, 14, 15, 16, 17, 18, 19, 20, 21, and 22): blue crab group beta. The FM numbers in each scale interval have been computed from the integrated FMs obtained with every five primers. The higher FM scales (>2,000 bp) are not observed in the two blue crab groups. FM, fragment. 
the Thirunelveli group (Nagarajan et al., 2006). DNA FM scales varied from $50 \mathrm{bp}$ to 1,600 bp. It has been reported that seven primers generated the scales of the DNA FMs also varied wildly, from 90 to 2,400 bp from the G. vermiculophylla (GRV) and G. chorda (GRC) (Kim \& Yoon, 2018). Group-related PCR FMs were identified in the Oujiang color carp (Wang \& Li, 2004) and the $\mathrm{F}_{1}$ hybrids of masu salmon Oncorhynchus masou masou and amago salmon O. m. ishikawae (Yamazaki et al., 2005). The frequencies of FMs generated by six primers were calculated in multiple catfish groups, as described in catfish (Liu et al., 1998).

The BS rate between party no. 01 of the blue crab group alpha and no. 19 of blue crab group beta was 0.094 that the lowermost was detected, as shown in Table 1 . The BS rate between party's no. 19 and no. 20 was 0.907 , which was the highest rate within the blue crab group beta. The five oligoprimers OPA-05, OPB-06, OPD-07, OPD-14, and OPD-01 were used to generate the number of ULSEG and number of LSTG. The 33 ULSEG in the blue crab sample generated by the OPD07 primer were approximately $800 \mathrm{bp}, 1,000 \mathrm{bp}$, and 1,600 bp in scale (Table 2). 55 ULSEG, with an average of 11 per primer, were detected in the blue crab group alpha. $88 \mathrm{FMs}$, with a mean of 17.6 per primer, were identified in the blue crab group beta. The oligonucleotide primer OPB-06 produced 22 ULSEG in the blue crab group alpha example and were about $150 \mathrm{bp}$ and $200 \mathrm{bp}$ in scale. The oligonucleotide OPD-01 primer uncovered 22 loci shared by all the samples of the two blue crab groups, as FMs of 1,000 bp (Table 2). The oligo-primer OPA-05 made ULSEG, almost $400 \mathrm{bp}$ and $500 \mathrm{bp}$, separately, in blue crab group beta. The remaining oligonucleotide primers did not reveal any loci shared by the two crab groups.

The average number of ULSEG was diverse and 1.6-fold higher in the crab group beta than in the crab group alpha. It has been reported that the initial screening of the 440 DNA primers identified 29 potential polymorphic markers associated with high or low color breeding values (Araneda et al., 2005). Also, only one primer showed a consistent amplification pattern (FM scale approximately $550 \mathrm{bp}$ ) associated with high color breeding value. Especially, only 6 of 16 salmon of low color breeding value showed the marker associated with color breeding value in the experimental group. Nagarajan et al. (2006) is stated that 14 were of a polymorphic nature and six were group-specific bands (distinctive bands) among the 42 DNA bands. Of the six group-specific bands, the Coimbatore group had five bands, whereas the Thirunelveli group had only one band. They proposed that the polymorphic and distinctive DNA bands can be used as genetic markers to select the breeders from the desired group for the purpose of selective breeding programs and to monitor the level of DNA variability in the wild or cultured group of the species.

Parties in the blue crab group beta $(0.601 \pm 0.017)$ had higher BS rates than did parties from the blue crab group alpha $(0.563 \pm 0.017)(p<0.05)$, as established in Table 3. The reported BS rates

Table 1. Number of ULSEG and LSTG amplified in two blue crab groups by 5 oligo-primers

\begin{tabular}{ccccc}
\hline \hline Item & \multicolumn{2}{c}{ No. of ULSEG } & & No. of LSTG \\
\cline { 1 - 2 } \cline { 1 - 2 } Primer $\backslash$ Group & Blue crab group alpha & Blue crab group beta & Two blue crab groups \\
\hline OPA-05 & 0 & 22 & 0 \\
OPB-06 & 22 & 11 & 0 \\
OPD-01 & 22 & 22 & 22 \\
OPD-07 & 11 & 33 & 0 \\
OPD-14 & 0 & 0 & 0 \\
\hline Total no. & 55 & 88 & 22 \\
\hline Average no. per primer & 11 & 17.6 & 4.4 \\
\hline
\end{tabular}

ULSEG, unique loci shared to each group; LSTG, loci shared by the two groups. 
Table 2. Similarity matrix, including BS rates of two groups of blue crab (P. trituberculatus) from the Yellow Sea of Korea

\begin{tabular}{|c|c|c|c|c|c|c|c|c|c|c|c|c|c|c|c|c|c|c|c|c|c|c|}
\hline & \multicolumn{11}{|c|}{ BS rates of blue crab group alpha } & \multicolumn{11}{|c|}{ BS rates of blue crab group beta } \\
\hline & 1 & 2 & 3 & 4 & 5 & 6 & 7 & 8 & 9 & 10 & 11 & 12 & 13 & 14 & 15 & 16 & 17 & 18 & 19 & 20 & 21 & 22 \\
\hline 1 & - & 0.331 & 0.513 & 0.563 & 0.408 & 0.704 & 0.442 & 0.718 & 0.162 & 0.440 & 0.350 & 0.345 & 0.275 & 0.269 & 0.264 & 0.260 & 0.276 & 0.252 & 0.094 & 0.094 & 0.419 & 0.132 \\
\hline 3 & & & - & 0.717 & 0.692 & 0.720 & 0.538 & 0.582 & 0.544 & 0.735 & 0.571 & 0.541 & 0.506 & 0.408 & 0.470 & 0.410 & 0.405 & 0.469 & 0.333 & 0.287 & 0.558 & 0.461 \\
\hline 4 & & & & - & 0.672 & 0.810 & 0.540 & 0.679 & 0.420 & 0.681 & 0.425 & 0.501 & 0.332 & 0.408 & 0.469 & 0.504 & 0.460 & 0.470 & 0.298 & 0.384 & 0.517 & 0.314 \\
\hline 7 & & & & & & & - & 0.451 & 0.567 & 0.561 & 0.584 & 0.490 & 0.456 & 0.561 & 0.516 & 0.562 & 0.577 & 0.456 & 0.359 & 0.319 & 0.703 & 0.335 \\
\hline 8 & & & & & & & & - & 0.411 & 0.536 & 0.441 & 0.505 & 0.297 & 0.400 & 0.423 & 0.422 & 0.415 & 0.391 & 0.333 & 0.328 & 0.486 & 0.337 \\
\hline 9 & & & & & & & & & - & 0.666 & 0.724 & 0.504 & 0.555 & 0.476 & 0.552 & 0.493 & 0.415 & 0.436 & 0.512 & 0.467 & 0.481 & 0.595 \\
\hline 10 & & & & & & & & & & - & 0.652 & 0.651 & 0.533 & 0.532 & 0.627 & 0.534 & 0.557 & 0.479 & 0.469 & 0.444 & 0.609 & 0.350 \\
\hline 14 & & & & & & & & & & & & & & - & 0.836 & 0.726 & 0.733 & 0.670 & 0.525 & 0.498 & 0.660 & 0.419 \\
\hline 15 & & & & & & & & & & & & & & & - & 0.691 & 0.673 & 0.658 & 0.619 & 0.596 & 0.559 & 0.457 \\
\hline 16 & & & & & & & & & & & & & & & & - & 0.846 & 0.789 & 0.515 & 0.469 & 0.719 & 0.401 \\
\hline 17 & & & & & & & & & & & & & & & & & - & 0.803 & 0.570 & 0.478 & 0.784 & 0.333 \\
\hline 18 & & & & & & & & & & & & & & & & & & - & 0.594 & 0.531 & 0.640 & 0.466 \\
\hline 19 & & & & & & & & & & & & & & & & & & & - & 0.907 & 0.499 & 0.592 \\
\hline 20 & & & & & & & & & & & & & & & & & & & & - & 0.427 & 0.582 \\
\hline 21 & & & & & & & & & & & & & & & & & & & & & - & 0.410 \\
\hline 22 & & & & & & & & & & & & & & & & & & & & & & - \\
\hline
\end{tabular}

BS, band-sharing..

Table 3. Statistical BS rates (mean \pm SE) between two blue crab groups obtained from the BS rates and similarity matrix

\begin{tabular}{ccc}
\hline \hline Group & Group alpha & Group beta \\
\hline Group alpha & $0.563 \pm 0.017^{\mathrm{b}}$ & $0.435 \pm 0.010^{\mathrm{c}}$ \\
Group beta & - & $0.601 \pm 0.017^{\mathrm{a}}$ \\
\hline
\end{tabular}

Each value is a result of three different experiments.

${ }^{a-c}$ Values with different superscript are significantly different, $p<0.05$.

BS, band-sharing.

between the two crab groups are inconsistent with the previously reported results (Yoon, 2020). To illustrate, the average BS rate illustrated by my study is also lower than the value reported for Chinese (0.788 \pm 0.014$)$ Urechis spp. groups (Yoon, 2019b), and masu salmon group (0.704) (Yoon, 2020).

The clustering analysis showed the GD of the two groups through a polar dendrogram obtained by the five oligo-primers. The dendrogram indicates two genetic groups such as cluster I (BLUECRAB 01, 03, 04, 05, 06, 08, and 10) and cluster II (BLUECRAB 02, 07, 09. 11, 12, 13, 14, 15, 16, 17, 18, 19, 20, 21, and 22), as shown in Fig. 2. The shortest genetic distance revealing significant molecular difference was between blue crab parties no. 17 and $16(\mathrm{GD}=0.050)$. Ultimately, party no. 11 in the blue crab group was utmost remotely linked to blue crab party no. $01(\mathrm{GD}=0.906)$. In teleost, this clustering analysis discovered a pattern in line with the one posited 


\section{Cluster Tree}

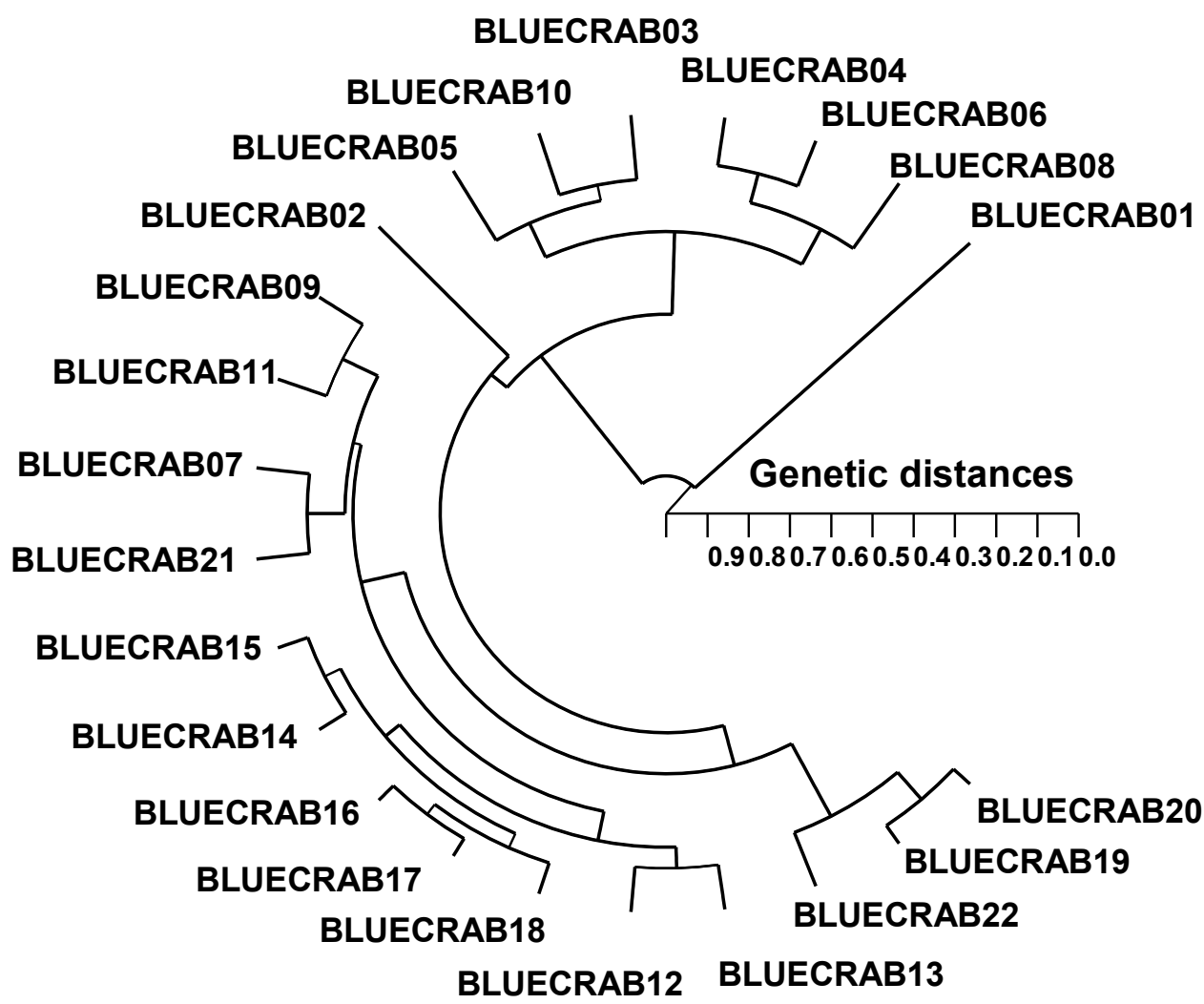

Fig. 2. Parallel of the 22 phenotypic traits of differential parties. Polar dendrogram acquired from the unweighted pair group method using arithmetic averages (UPGMA) analysis of two groups of blue crab (Portunus trituberculatus) based on pairwise values for unbiased genetic identity. The genetic rapport between different parties from cluster I (BLUECRAB 01, 03, 04, 05, 06, 08, and 10) and cluster II (BLUECRAB 02, 07, 09. 11, 12, 13, 14, 15, 16, 17, 18, 19, 20, 21, and 22) was formed by clustering analysis on the basis of genetic identity.

by Nagarajan et al. (2006). Among the three Channa punctatus groups collected from three rivers of south India, the highest genetic identity ( $\mathrm{GD}=0.9231$ ) was found between Thirunelveli and Quilon groups (Nagarajan et al., 2006). They also demonstrated that Thirunelveli and Quilon groups are more related to each other than to the Coimbatore group. This study showed that large genetic differences could be found between geographical groups within a group, as well as between groups.

Various researchers analyzed the scale of DNA FMs in the PCR products of lentil (Lens spp.) (Eujayl et al., 1998), yellowfin tuna (Thunnus albacares) (Diaz-Jaimes \& Uribe-Alcocer, 2003), Amazonian fish matrincha (Brycon cephalus) (Wasko et al., 2004), Chryseobacterium strains (Bernardet et al., 2005), spotted murrel (Channa punctatus) (Nagarajan et al., 2006), crayfish (Cambaroides similis) (Yoon et al., 2006), cuttlefish (Sepia esculenta) (Yoon \& Kim, 2010), and white clam (Meretrix lusoria) (Yoon et al., 2012). The apparent primer revealed significant differences in parties and groups, resulting from variations in DNA polymorphisms among parties and groups (Archak et al., 2003; Diaz-Jaimes \& Uribe-Alcocer, 2003; Wang \& Li, 2004; Wasko et al., 2004; Nagarajan et al., 2006; Yoon et al., 2006; Yoon \& Kim, 2010; Yoon et al., 2012; Yoon, 2019b).

As stated before, the capacity of PCR analysis to ascertain pinpointing markers for the recognition of two blue crab groups has been validated. Basically, the grouping of crab species 
is founded on morphological characteristic in claw type, claw scale, form style, figure size, physique color, carapace style, and carapace scale. It is expected by Yue \& Orban (2005) that the application of this method facilitates studies that require high-throughput DNA isolation for PCR amplification, such as genotyping by microsatellites for mapping and genetic diversity studies, as well as mutant screening in zebrafish.

\section{REFERENCES}

Almeida FS, Sodré LMK, Contel EPB (2003) Population structure analysis of Pimelodus maculatus (Pisces, Siluriformes) from the Tietê and Paranapanema rivers (Brazil). Genet Mol Biol 26:301-305.

Araneda C, Neira R, Iturra P (2005) Identification of a dominant SCAR marker associated with colour traits in coho salmon (Oncorhynchus kisutch). Aquaculture 247:67-73.

Archak S, Gaikwad AB, Gautam D, Rao EVVB, Swamy KRM, Karihaloo JL (2003) Comparative assessment of DNA fingerprinting techniques (RAPD, ISSR and AFLP) for genetic analysis of cashew (Anacardium occidentale L.) accessions of India. Genome 46:362-369.

Bernardet JF, Vancanneyt M, Matte-Tailliez O, Grisez L, Tailliez P, Bizet C, Nowakowski M, Kerouault B, Swings J (2005) Polyphasic study of Chryseobacterium strains isolated from diseased aquatic animals. Syst Appl Microbiol 28:640-660.

Cho EM, Min GS, Kanwal S, Hyun YS, Park SW, Chung KW (2009) Phylogenetic analysis of mitochondrial DNA control region in the swimming crab, Portunus trituberculatus. Anim Cells Syst 13:305-314.

Cho KJ (2007) Studies on an artificial feed development for blue crab (Portunus trituberculatus) grower. M.S. Thesis, Kangwon National University, Samcheok, Korea. p 54.

Diaz-Jaimes P, Uribe-Alcocer M (2003) Allozyme and RAPD variation in the eastern Pacific yellowfin tuna (Thunnus albacares). Fish Bull 101:769-777.

Eujayl I, Baum M, Powell W, Erskine W, Pehu E (1998) A genetic linkage map of lentil (Lens sp.) based on RAPD and AFLP markers using recombinant inbred lines. Theor Appl Genet 97:8389.

Jo HS, Park WG, Kwon DH, Cha BY, Im YJ (2013) Distribution and occurrence of swimming crab, Portunus trituberculatus larvae in the mid-western coast of Korea in the Yellow Sea. J Fish Mar Sci Educ 25:991-997.

Kang JC (1997) Acute toxicity of hydrogen sulfide to larvae and adults of blue crab Portunus trituberculatus white shrimp Metapenaeus monoceros and prawn Macrobrachium nipponens. J Fish Pathol 10:65-72.

Kim JH, Park GS (2014). Quality characteristics of kimchi added with blue crab. Culin Sci Hosp Res 20:246-259.

Kim YS, Yoon JM (2018) Genetic distances in two Gracilaria species (Gracilariaceae, Rhodophyta) identified by PCR technique. Dev Reprod 22:393-402.

Lee HJ, Yoon SJ, Hyun YS, Kim HJ, Hwang SI, Bae JS, Chung KW (2013) Analysis of microsatellite loci for swimming crab Portunus trituberculatus populations in the Korean side of the Yellow Sea.J Life Sci 23:1088-1095.

Lee H, Yang J (2005) An optimal management model with regard to the swimming crabs in Yellow sea Yeonpyongdo in Korea: Simulation and implications. Int Area Stud Rev 19:423-443.

Liu Z, Li P, Argue BJ, Dunham RA (1998) Inheritance of RAPD markers in channel catfish (Ictalurus punctatus), blue catfish (I. furcatus), and their $\mathrm{F}_{1}, \mathrm{~F}_{2}$ and backcross hybrids. Anim 
Genet 29:58-62.

Liu ZJ, Cordes JF (2004) DNA marker technologies and their applications in aquaculture genetics. Aquaculture 238:1-37.

Maltagliati F (1998) A preliminary investigation of allozyme genetic variation and population geographical structure in Aphanius fasciatus from Italian brackish-water habitats. J Fish Biol 52:1130-1140.

Nagarajan M, Haniffa MA, Gopalakrishnan A, Basheer VS, Muneer A (2006) Genetic variability of Channa punctatus populations using randomly amplified polymorphic DNA. Aquac Res 37:1151-1155.

Pyen CK (1970) Propagation of the blue crab, Portunus trituberculatus (MIERS). Bull Korean Fish Soc 3:187-198.

Seo HC, Jang IK, Cho YR, Kim JS, Kim BR (2009) Gonad maturation and spawning of the blue crab, Portunus trituberculatus (Miers, 1876) from the West Sea of Korea. Korean J Fish Aquat Soc 42:48-55.

Wang C, Li SF (2004) Phylogenetic relationships of ornamental (koi) carp, Oujiang color carp and long-fin carp revealed by mitochondrial DNA COII gene sequences and RAPD analysis. Aquaculture 231:83-91.

Wasko AP, Martins C, Oliveira C, Senhorini JA, Foresti F (2004) Genetic monitoring of the Amazonian fish matrinchã (Brycon cephalus) using RAPD markers: Insights into supportive breeding and conservation programmes.J Appl Ichthyol 20:48-52.

Yamazaki Y, Shimada N, Tago Y (2005) Detection of hybrids between masu salmon Oncorbynchus masou masou and amago salmon O. m. ishikawae occurred in the Jinzu river using a random amplified polymorphic DNA technique. Fish Sci 71:320-326.

Yeon IJ, Lee YS, Song MY, Park WG (2011) Seasonal timing and distribution of Charybdis japonica (Decapoda: Portunidae) larvae off Yeonpyeong-do in the Yellow Sea, Korea. Korea J Fish Aquat Sci 44:162-166.

Yoon JM (2019a) Genetic distances within-population and between-population of tonguesole, Cynoglossus spp. identified by PCR technique. Dev Reprod 23:297-304.

Yoon JM (2019b) Genetic distances between two echiuran populations discriminated by PCR. Dev Reprod 23:377-384.

Yoon JM (2020) Genetic distances of rainbow trout and masu salmon as determined by PCRbased analysis. Dev Reprod 24:241-248.

Yoon JM, Kim JY (2010) Genetic differences and geographic variation in cuttle fish (Sepia esculenta Hoyle). Dev Reprod 14:163-170.

Yoon JM, Kim YH, Kim S (2006) Genetic variation in geographic crayfish (Cambaroides similis) populations.J Fish Pathol 19:141-153.

Yoon JM, Park KI, Choi SH (2012) Variation of shell color in three geographic white clam (Meretrix lusoria) populations of the Yellow Sea. Dev Reprod 16:47-51.

Yue GH, Orban L (2005) A simple and affordable method for high-throughput DNA extraction from animal tissues for polymerase chain reaction. Electrophoresis 26:3081-3083. 